
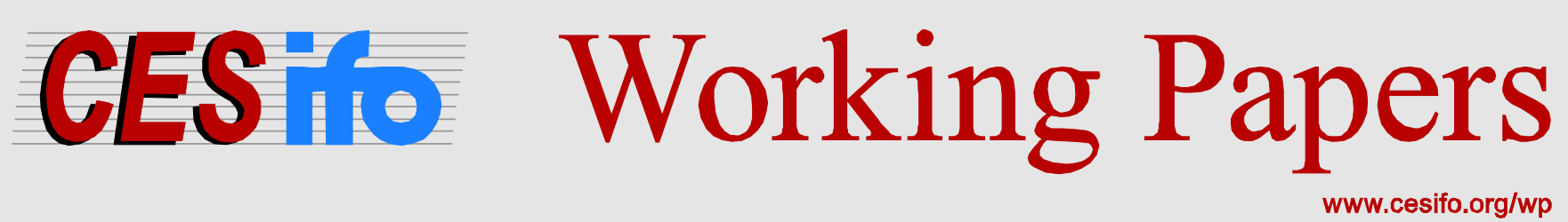

\title{
Secular Stagnation: Insights from a New Keynesian Model with Hysteresis Effects
}

\author{
Bas van Aarle \\ CESIFO WORKING PAPER NO. 5797 \\ CATEgory 6: Fiscal POLICY, MACROECONOMICS AND GROWTH \\ MARCH 2016 \\ An electronic version of the paper may be downloaded \\ - from the SSRN website: Www.SSRN.com \\ - from the RePEc website: Www.RePEc.org \\ - from the CESifo website: www.CESifo-group.org/wp
}




\title{
Secular Stagnation: Insights from a New Keynesian Model with Hysteresis Effects
}

\begin{abstract}
To analyse the most important aspects of the Secular Stagnation hypothesis, this paper considers the effects of hysteresis in potential output in a New-Keynesian model that is extended with endogenous potential output. To do so, a number of simulations of relevant scenarios is undertaken. It is demonstrated that extending the New-Keynesian model with hysteresis has a number of crucial implications for macro-economic adjustment and macro-economic management. It is indicated how the model can contribute to a better understanding of a number of important elements of the Secular Stagnation hypothesis.
\end{abstract}

JEL-Codes: E310, E430, E620, H620.

Keywords: potential output hysteresis, monetary policy, fiscal policy.

Bas van Aarle

Leuven Center for Irish Studies

Janseniusstraat 1

Belgium - 3000 Leuven

bas.vanaarle@econ.kuleiven.be

February 25, 2016

I am grateful for the comments made by two anonymous referees. 


\section{Introduction}

In recent years, many countries recovered only very slowly from the Great Recession that resulted from the Global Financial Crisis of 2008. In most European countries e.g., output and employment growth has been small if positive at all and output and employment levels are struggling to reach pre-crisis levels. Policymakers and economists indeed have a difficult time in providing a complete explanation for the observed shallowness of recovery and in finding the most effective policy responses in these difficult conditions.

A recent debate -"the Secular Stagnation hypothesis"- seeks to provide a better understanding of this very slow recovery. Summers (2014) summarizes this debate as follows: "The new Secular Stagnation hypothesis responds to recent experience and the manifest inadequacy of conventional formulations by raising the possibility that it may be impossible for an economy to achieve full employment, satisfactory growth and financial stability simultaneously simply through the operation of conventional monetary policy. It thus provides a possible explanation for the dismal pace of recovery in the industrial world and also for the emergence of financial stability problems as an increasingly salient concern."

In the Secular Stagnation scenario the output effects of the crisis persist, and actual output levels do not seem to return to (pre-crisis) potential output levels for a protracted period. One possible explanation for this phenomenon is the hysteresis hypothesis: the observed Secular Stagnation could reflect a permanent drop in potential output and employment as a consequence of the endogenous adjustment effects that have been triggered by the Financial Crisis. Hysteresis effects of current output on future potential output operate through the effect that a current reduction in investment has on future capital and through the effect of current unemployment on worker skills and labor force attachment. Hysteresis is not easy to prove: what adds to the difficulties in the analysis of hysteresis, is that potential output is an unobservable variable: it is actually very difficult to pin down in the real world. In fact, it can not be excluded that potential output had been overestimated in the boom-period before the financial crisis.

An other important feature of the Secular Stagnation debate is the possibility of excess savings that would require real interest rates to be very low or even negative for an extended time. In a recent narrative policy study on secular stagnation coordinated by Teulings and Baldwin (2014), a number of crucial demand (adverse demographic trends, fiscal stringency, monetary policy impotence due to zero lower bound, over-indebtedness causing excess-saving and a 'balance-sheet' recession) and supply factors (lack of innovation, slowdown in efficiency, sclerotic factors in the labour market) are identified that could explain the Secular Stagnation.

To analyse the most important aspects of the Secular Stagnation hypothesis, this paper considers the effects of hysteresis in potential output in a New-Keynesian model that is extended with hysteresis in potential output. To do so, a number of simulations of relevant scenarios is undertaken. It is demonstrated that such an extension of a standard New Keynesian model with hysteresis has a number of crucial implications for macro-economic adjustment and macro-economic management. It is indicated how the model can indeed help us to understand a number of important elements of the Secular Stagnation hypothesis.

This paper is organised in as follows: Section 2 discusses the Secular Stagnation Hypothesis, focusing on the effects of the financial crisis and its aftermath on potential output. Section 3 provides a New-Keynesian analytical framework that is extended with hysteresis effects. Section 4 uses numerical simulations of a stylised example to illustrate the workings of the model and relates the results to the context of Europe's very slow recovery crisis and the current discussions about fiscal 
management in the Euro Area and structural reform policies. Section 4 concludes.

\section{The financial crisis, (potential) output and the Secular Stagnation Hypothesis}

The very sluggish output and employment recovery in Europe and elsewhere from the financial crisis and ensuing recession, has led economists and policy makers increasingly to consider the possibility that the Great Recession is not an ordinary recession from which the economy could recover relatively quickly. Instead, they argue, this period of very slow growth may actually point at deeper, structural problems that prevent a quick recovery so far. In several studies on the recent financial crisis and Great Recession, it has been pointed out that in many OECD countries a substantial potential output loss (in the order of 5 to 10 percent of GDP) occurred as a result of the Great Recession. European Commision (2009), OECD (2009), Furceri and Mourouganne (2012), Ball (2014), Ollivaud and Turner (2014), Anderton et. al. (2014) are all detailed empirical studies that seek to estimate effects of the financial crisis on potential output and employment finding evidence for such a substantial loss in potential output.

It is important to understand how the financial crisis could lead to such a drop in the (actual and potential) output level and/or growth rate and how persistent such a drop could be. The adverse effects on potential output would result from the impact of the financial crisis on its three main determinants: the stock of capital, the amount of labour and technology, as reflected in Total Factor Productivity (TFP). The financial crisis and recession have reduced investment in new capital and technology: investment opportunities declined and credit from banks became more scarce as banks became more concerned about credit risk. The recession has also reduced opportunities in the labour market. There is the accompanying risk that the increase in unemployment as a result of the crisis turns into an increase in structural unemployment as worker skills deteriorate with longer spells of unemployment.

The "hysteresis hypothesis" assumes that the economy retains a memory of the shocks associated with recessions, implying path-dependence in macro-economic adjustments. Hysteresis has pervasive implications for macroeconomic adjustment and policy. It opens up the possibility that temporary shocks may have permanent effects in the economy, in particular a permanent drop in the level of potential output and an increase in structural unemployment. Hysteresis results from capital scrapping and labour market rigidities (including the well-known "insider/outsider" conflicts), that prevent/discourage many unemployed workers to re-enter employment again after the recession. The high rate of joblessness and long duration of joblessness, discourages workers further and will result in a permanent destruction of human capital when discouraged workers exit their labour market search.

A significant literature on hysteresis resulted from the experiences of the 1970s and 1980s when after the first and second Oil Crisis and ensuing recessions, unemployment displayed the "ratcheteffect" that is characteristic for hysteresis. In both cases, unemployment failed to drop to the level before the recession and stayed stubbornly high. ${ }^{1}$ Clearly countries are likely to differ in the degree to which hysteresis is affecting the economy at a certain moment. These differences reflect the underlying

\footnotetext{
${ }^{1}$ See e.g. Bruno and Sachs (1985), Blanchard and Summers (1986), (1987) and (1988), and Lindbeck and Snower (1986) on the hysteresis experiences of associated with the first and second Oil Crisis of the 1970s and 1980s. The related empirical debate about unit roots in output (Stock and Watson (1986) and Diebold and Rudebusch (1987)) also dates back to the same period.
} 
institutional settings, the impact of various shocks and the policy reactions. Some countries were less affected e.g. by the Great Recession than others for whom hysteresis could be a serious concern.

Another theoretical literature that is also of some relevance for our analysis studies the effect of output gap uncertainty on monetary and fiscal policy management, see e.g. Ehrmann and Smets (2003). This literature takes as a starting point the observation that policy makers face incomplete information about current economic conditions, and in particular about potential output. Potential output is an unobservable variable, resulting in uncertainty about its actual adjustment. As a result, policy makers have to form estimations/expectations about the actual level of potential output (and its growth rate) and consequently of the actual output gap. As a result of this uncertainty, potential output and the output gap are often subject to significant revisions, especially during crisis periods. This uncertainty makes it difficult to evaluate the adequateness of current monetary and fiscal policy from the perspective of business cycle stabilization. This literature concludes that more potential output uncertainty requires more caution in setting policies as the possibility of policy errors in increased. This literature, however, focuses on output gap uncertainty and does not consider the possibility of hysteresis as a source of endogenous business cycle fluctuations. ${ }^{2}$

A consequence of the Financial Crisis and Great Recession is higher uncertainty surrounding estimates of potential output compared to the previous decade of Great Moderation. This uncertainty is evident in the continued downward revisions in the estimates of potential output growth for almost all OECD countries during the Great Recession since 2008. It is not therefore not clear in the wake of the observed very weak recovery of output and employment, what are the most realistic expectations concerning potential output and employment in the near and more distant future. This depends also on which scenario is most likely concerning the impact the financial crisis has had on potential output growth.

Three possible scenarios concerning the effects of the financial crisis on the potential output level and its growth-rate in the long-run are distinguished in Figure 1. First is one-off changes in the level of GDP without a change in long-run potential output level and its growth rate (green lines). In this scenario, after the Great Recession, economic recovery will eventually bring the economy again on the pre-crisis growth path in the long run. While the recession could be deep and persistent, this scenario would imply that the output loss is eventually recovered. Second is the possibility of a permanent decline in the potential output level without a change in the long-run potential growth rate (blue lines). This scenario is equivalent to hysteresis in output and unemployment. Third, is a permanent drop in the potential output level and long-run potential growth rate, resulting in a form of "super-hysteresis" (red lines).

In mainstream macroeconomic models, hysteresis is not considered given the complexities it entails in terms of theory, empirical estimation and policy analysis. Hysteresis implies that a temporary shock has permanent effects so that the economy does not return to the initial steady-state but adjusts to a new -endogenous- steady-state, an aspect that we will demonstrate in detail in the numerical analysis. In a similar vein, empirical analysis is also complicated by hysteresis: in case of hysteresis, variables contain a unit-root so that the second and higher order moments of variables

\footnotetext{
${ }^{2}$ The standard New Keynesian models and their more worked out DSGE variants rely on exogenous business cycle fluctuations in the sense that economic adjustments are the result of various types of shocks that hit the economy and transmit themselves through various transmission channels -exogenous transmission of shocks in other words- after which the economy returns to steady-state. In case of endogenous fluctuations like in case of hysteresis, shocks also imply that the transmission of shocks is endogenous since the steady-state itself is also affected by the temporary shock.
} 


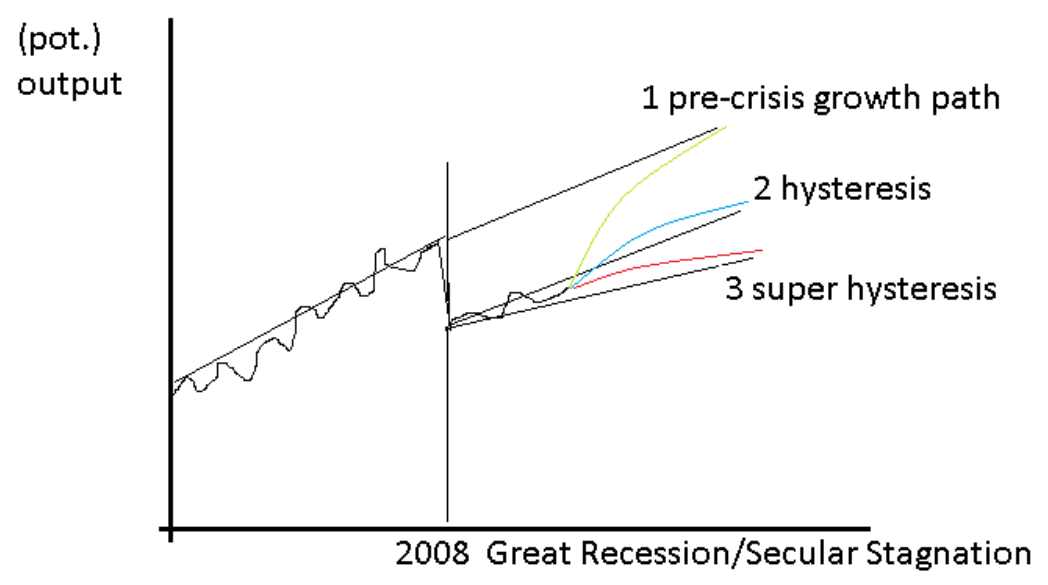

Figure 1: Effects of the financial crisis on the level and growth rate of potential output (hypothetical potential and actual output series).

are not defined. Estimation and measurement errors of the true potential output/output gap will translate in policy errors: in particular policy makers are faced with the uncertainty whether actual output and inflation adjustment reflects the occurrence of potential output shocks or is caused by other shocks: demand shocks, mark-up shocks etc. E.g. an overestimation of potential output implies an overestimation of the output gap in times of recession, inducing policy makers to policies that could be inflationary in the short-run and the fiscal stance is likely to be to lax from the perspective of the true potential output. In a similar manner, in case of underestimation of potential output, macroeconomic policies could be too restrictive and risk to contribute to deflationary pressures.

\section{The Analytical Framework}

Our analytical framework follows the baseline New Keynesian model as a description of the behavior of macroeconomic variables (e.g., Woodford (2003), Gali (2008)). The adjustment of output, inflation and interest rates is described by the dynamic IS curve (1), the (hybrid) New Keynesian Phillips curve (2), and dynamic Taylor rules that characterise monetary policy (3), and fiscal policy (4). In addition to these standard equations, we add dynamics of potential output (5) as we would like to analyse the consequences of hysteresis in potential output. The dynamic IS curve summarizes the aggregate goods demand in the economy:

$$
y_{t}=\omega E y_{t+1}+(1-\omega) y_{t-1}-\sigma\left(i_{t}-E \pi_{t+1}-r_{t}^{n}\right)+g_{t}+\epsilon_{t}^{y}
$$

in which $y$ denotes real output, $i$ the short-term nominal interest rate, $\pi$ the rate of inflation in the general price level, $r^{n}$ the natural or equilibrium real interest rate, $g$ net government spending, $\epsilon^{y}$ is an aggregate demand shock. The subscript $t$ refers to time, $E$ is the expectations operator.

In this reduced form output depends on past output, expected future output, the real interest rate (expressed as a deviation from the natural real interest rate), net government spending, and a demand shock. The backward-looking component in the IS curve results the fraction of consumers that are backward-looking because of habit formation in consumption decisions (or because they face 
credit constraints). The forward-looking part is produced by rational, inter-temporally maximizing agents that apply the principles of optimal consumption-smoothing.

All macroeconomic shocks in the model -demand shocks $\left(\epsilon^{y}\right)$, cost-push shocks $\left(\epsilon^{\pi}\right)$, monetary shocks $\left(\epsilon^{i}\right)$, fiscal shocks $\left(\epsilon^{g}\right)$, potential output shocks $\left(\epsilon^{\bar{y}}\right)$, natural interest rate shocks, $\left(\epsilon^{r n}\right)$ - are assumed to follow stationary $\operatorname{AR}(1)$ processes, $\epsilon_{t}^{j}=\nu_{j} \epsilon_{t-1}^{j}+v_{t}^{j}$ where all innovations are white noise innovations, and all innovations are assumed to be contemporaneously uncorrelated. ${ }^{3}$

Inflation adjusts according to a hybrid New Keynesian Phillips-curve which contain elements of both forward and backward-looking price setting. In addition, the output gap as a measure of demand-pull inflation, and mark-up shocks $\epsilon^{\pi}$ affect inflation:

$$
\pi_{t}=\beta E \pi_{t+1}+(1-\beta) \pi_{t-1}+\kappa x_{t}+\epsilon_{t}^{\pi}
$$

The output gap $x_{t}=y_{t}-\bar{y}_{t}$ measures the distance between actual output and potential output, $\bar{y}_{t}$.

A Taylor rule with partial adjustment will be used as an approximation of monetary policy decisions in the economy. The monetary authority is assumed to set the short-term nominal interest rate, in response to movements in inflation and the output gap. $\rho_{i}$ measures inertia in interest rate adjustment, $\chi_{\pi}$ and $\chi_{x}$ are reaction coefficients to inflation and output gap, $\bar{\pi}$ is an inflation target.

$$
i_{t}=\rho_{i} i_{t-1}+\left(1-\rho_{i}\right)\left(r_{t}^{n}+\bar{\pi}+\chi_{\pi} \pi_{t}+\chi_{x} x_{t}\right)+\epsilon_{t}^{i}
$$

The feedback on inflation and output gap are standard arguments in the Taylor rule, the weights given to both objectives are given by the reaction coefficients $\chi_{\pi}$ and $\chi_{x}$. The degree of instrument smoothing is measured by $\rho_{i}$, where $0<\rho_{i}<1$. If $\rho_{i}$ goes to zero the original Taylor rule, which ignores instrument-smoothing, is obtained. If $\rho_{i}$ goes to one, monetary policy is increasingly smoothed over time.

Fiscal policy is given by a Taylor rule as well:

$$
g_{t}=\rho_{g} g_{t-1}+\left(1-\rho_{g}\right)\left(\bar{g}-\mu x_{t}\right)+\epsilon_{t}^{g}
$$

according to which net government spending responses to movements in the output gap. $\rho_{g}$ measures inertia budgetary adjustment, $\bar{g}$ is a net government spending target, $\epsilon^{g}$ denotes a budgetary shock.

The standard New Keynesian model assumes potential output to be constant (possibly subject to stochastic shocks) in order to focus on short-run fluctuations in output as a result of shocks to consumer preferences, labour supply shocks, firms' mark-up shocks, technological shocks and policy shocks. For our purpose it is more useful to consider endogenous adjustment of potential output, reflecting the possibility of hysteresis. The standard New Keynesian model does not consider hysteresis, therefore we introduce endogenous potential output into the model in the following way:

$$
\bar{y}_{t}=\rho_{\bar{y}} \bar{y}_{t-1}+\alpha y_{t-1}+\epsilon_{t}^{\bar{y}}
$$

Potential output depends on past potential output, actual output and potential output innovations, $\epsilon^{\bar{y}}$. In case $\alpha=0$ the model reduces to the standard New Keynesian model with exogenous potential

\footnotetext{
${ }^{3}$ Strictly speaking, in the hysteresis case, these shocks need to be considered/implemented as deterministic processes, given that the mean and variance of the output and potential output variables are not defined in the hysteresis case, as hysteresis implies that the various shocks can have permanent effects on the mean of potential and actual output, viz. potential and actual output are following random walks.
} 
output, in case $\alpha=1$, potential output displays hysteresis. In the intermittent case, $0<\alpha<1$, potential output dynamics are persistent. We will consider a value $\alpha=0.5$ to study this intermittent case.

In their analysis on the impact of potential output persistence on optimal monetary policy, Kienzler and Schmid (2014) consider values of $\alpha$ between 0 and 0.5 and demonstrate the need for additional monetary policy activism (in terms of reacting to temporary shocks) in the presence of potential output gap persistence. The intuition of this outcome is found in the stronger effects of shocks (and therefore of societal welfare in terms of output and inflation volatility), the stronger is the persistence in potential output. They refer to these cases with potential output persistence as hysteresis. This seems somewhat confusing. As we will see it is more useful to reserve hysteresis for the case $\alpha=1$, and persistent potential output for to the case where $0<\alpha<1$, since both cases are fundamentally different in the resulting adjustment dynamics.

\section{Numerical Results}

In this section, we simulate a number of relevant scenarios for the New-Keynesian hysteresis model (1)-(5). We consider the effects of: (i) a temporary negative demand shock, (ii) a one-off positive cost-push shock, (iii) a temporary negative shock to the natural interest rate, (iv) varying the degree of fiscal stabilization and, (v) a temporary negative demand shock that is accompanied by structural reform effort. The simulations assume the set of baseline model parameters presented in Table 1. These parameters were not empirically estimated but chosen based on plausibility and their usefulness as a baseline. A caveat therefore applies: small changes in this set of baseline parameters will lead to quantitative changes in outcomes, bigger changes may also change outcomes qualitatively.

\begin{tabular}{|c|c|c|c|c|c|c|c|}
\hline$\omega$ & 0.5 & $\bar{\pi}$ & 0 & $\rho_{\bar{y}}$ & 0.5 & $\nu_{\epsilon^{\bar{y}}}$ & 0.25 \\
\hline$\sigma$ & 1.0 & $\chi_{\pi}$ & 1.5 & $\alpha$ & {$[0,0.5,1]$} & $\nu_{\epsilon^{g}}$ & 0.0 \\
\hline$\beta$ & 0.5 & $\chi_{x}$ & 0.5 & $\nu_{\epsilon^{y}}$ & 0.5 & $\nu_{\epsilon^{r}}$ & 0.5 \\
\hline$\kappa$ & 0.1 & $\rho_{g}$ & 0.5 & $\nu_{\epsilon^{\pi}}$ & 0.0 & $\bar{g}$ & 0 \\
\hline$\rho_{i}$ & 0.5 & $\mu$ & 0.5 & $\nu_{\epsilon^{i}}$ & 0.0 & & \\
\hline
\end{tabular}

Table 1: Baseline parameter set.

\subsection{Effects of a temporary demand shock}

A crucial implication of hysteresis is the possibility that temporary shocks can have permanent effects on output and unemployment (through the hysteresis effects on potential output): in the long output is at a lower level than it would have been in the absence of the shock. We can illustrate of the workings of hysteresis in our model by considering the impact and transmission of a temporary demand shock. Figure 2 displays the effects of a negative demand shock in period 1 and its subsequent transmission in (potential), output, output gap, inflation, interest rate and net government spending. The blue line gives adjustment in the case of the standard New Keynesian model without hysteresis $(\alpha=0)$, the green lines give adjustment in the persistent potential output case $(\alpha=0.5)$, and red lines give the adjustment under hysteresis, $(\alpha=1)$.

The implications of hysteresis are quite clearly demonstrated by this example. While in the standard New Keynesian model and in the persistent potential output case, output returns to the 

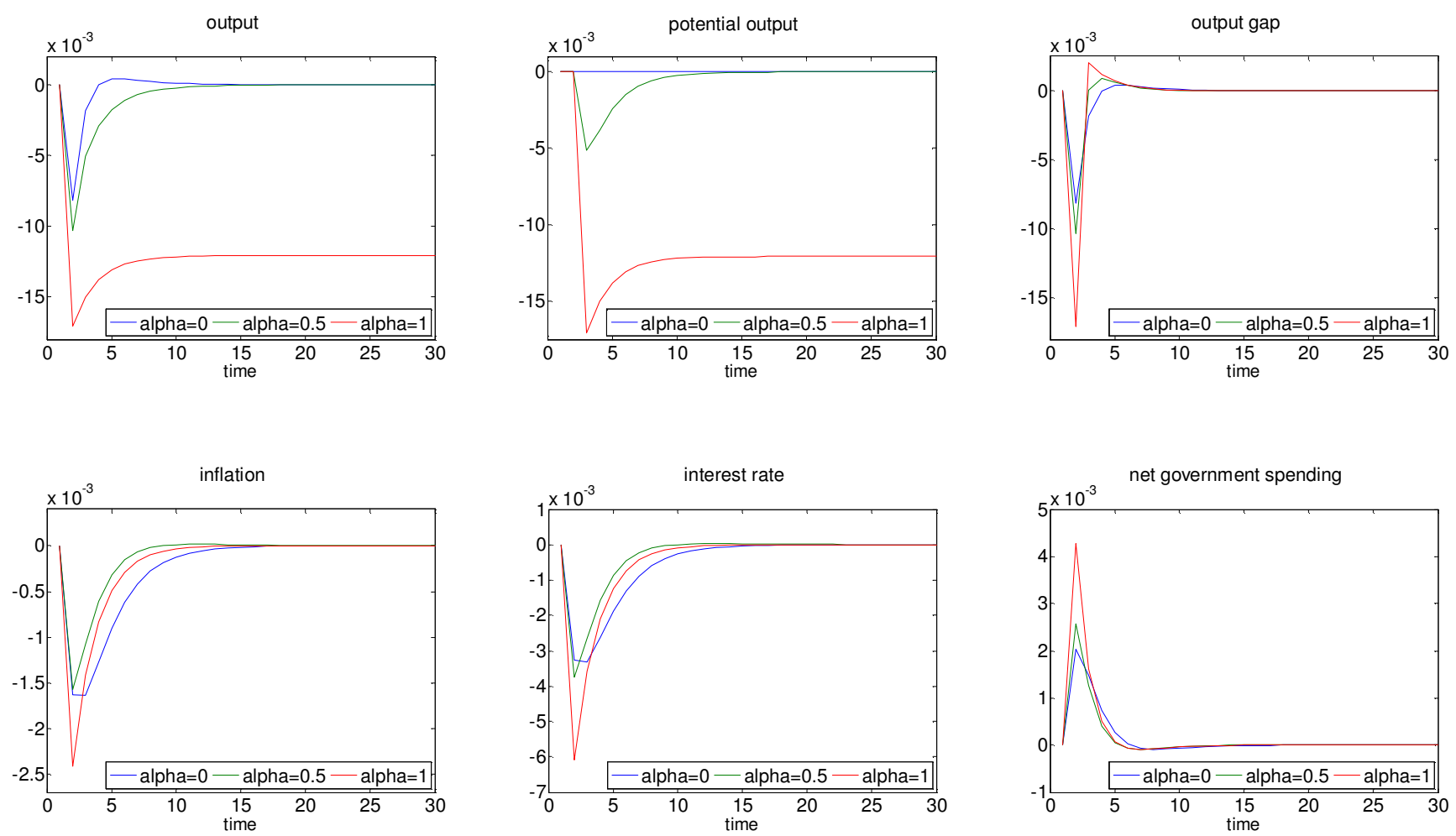

Figure 2: Effects of a temporary negative demand shock.

initial output level after a temporary recession, it fails to do so in the hysteresis case. The reason that it fails to do so is exactly the permanent drop in potential output in the hysteresis case. Given the New-Keynesian Phillips curve, the output gap is closed and inflation disappears once the temporary shock has faded out. Active monetary and fiscal policies in form of lower interest rates and higher net government spending contribute to the adjustment dynamics, but cannot prevent the long-run drop in (potential) output in the hysteresis cases. In case of hysteresis in potential output, the temporary shock is detrimental in the long run and active stabilization policies are desirable as they contribute cushioning the initial impacts of shocks and their subsequent transmissions in the wider economy.

\subsection{Effects of a temporary cost-push shock}

Mark-up/cost-push like oil price or wage cost shocks are another important sources of macroeconomic fluctuations. Mark-up shocks in the real world and in the New-Keynesian, create even more complications for policy makers than demand shocks since inflation is only indirectly controlled by the influence of active policies on the output gap. In case mark-up shocks occur, the monetary policy 
maker is facing a dilemma between actively stabilizing output by setting lower interest rates (and to accept the higher inflation resulting from expansionary monetary policy) or to stabilise inflation by raising interest rates (and accept the resulting temporary output loss). Figure 3 considers the effects of one-off one percent positive cost-push shock in period 1.
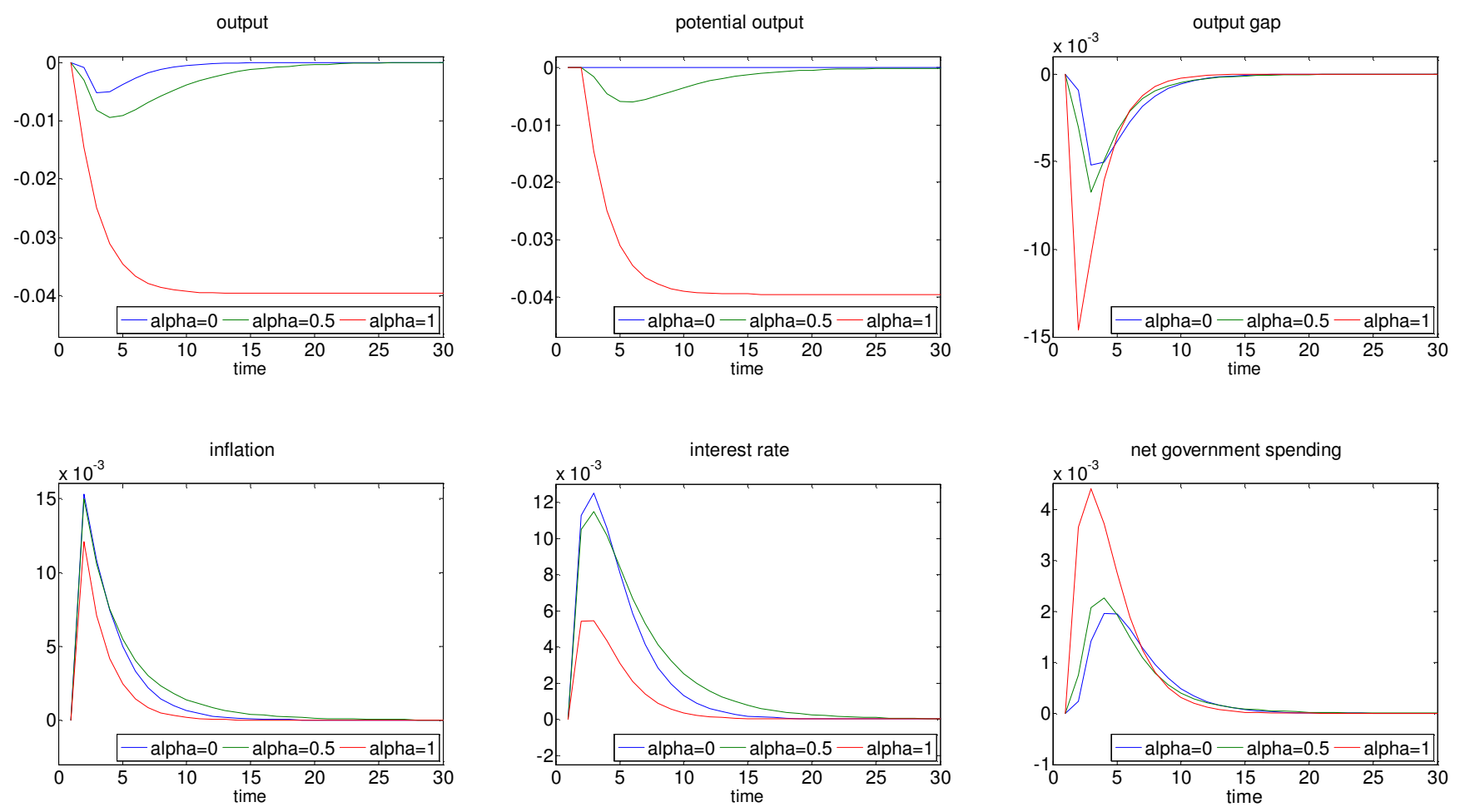

Figure 3: Effects of a one-off positive cost-push shock.

The mark-up shock creates stagflation: output drops and inflation increases. In the no-hysteresis case, the New-Keynesian model displays a convergence to the initial output level over time since potential output is unaffected. Monetary and fiscal stabilization policies are relatively ineffective, they just moderate inflation and/or output during the adjustment to the initial output level. In case of hysteresis, adjustment is different as the economy would settle for a lower potential and actual output level due to the hysteresis channel. This increases also significantly the potential role for fiscal and monetary stabilization policies: these policies can contribute to moderating the eventual actual and potential output drop as a result of the temporary shock. 


\subsection{Effects of a shock to the natural rate of interest}

The natural or equilibrium rate of interest is defined as the interest rate that would produce an aggregate demand equal to the natural rate of output, the rate of output that prevails if prices are fully flexible. The natural rate of interest in other words represents a neutral monetary policy stance. According to Summers (2014) and other observers, one factor that has also been connected to the Secular Stagnation hypothesis is a decline in the equilibrium real rate of interest. This drop reflects imbalances between global savings (which have increased) and global investment (which has decreased as a that result of the Financial Crisis). In cases like these where the natural rate of interest and inflation are approaching zero, conventional monetary policy is increasingly impotent to stimulate the economy since that would require setting interest rates below zero. Figure 4 demonstrates the effects in the New-Keynesian model with hysteresis of a temporary one percent negative shock to the natural rate of interest $r_{t}^{n}$ in period 1.
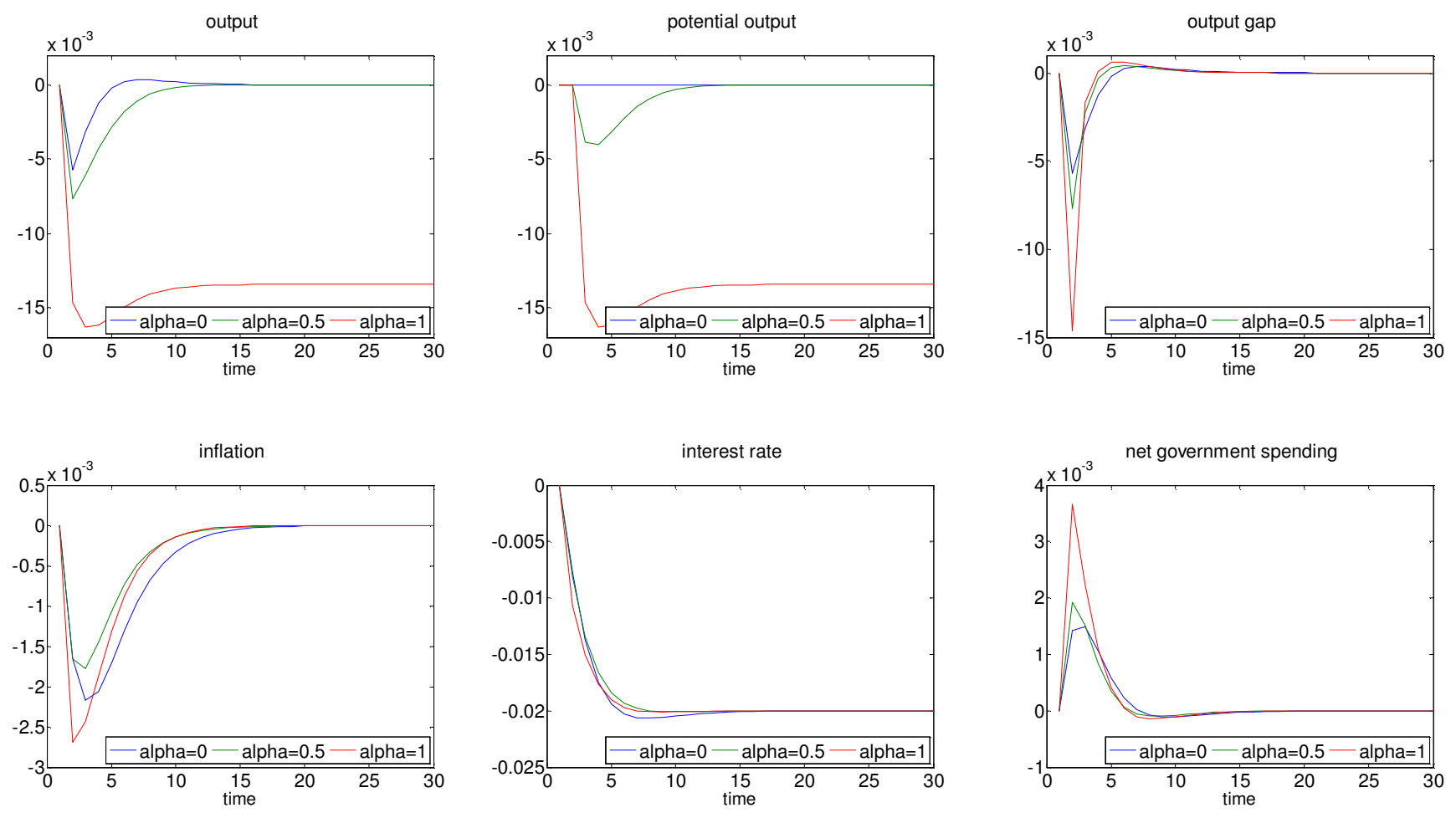

Figure 4: Effects of a temporary negative natural interest rate shock.

The simulations of the model of this shock are in line with the intuitions of Summers (2014) and 
other observers. The drop in the natural rate of interest provokes a recessionary and deflationary spiral. In the no-hysteresis regime, the economy recovers quite quickly also helped by expansionary monetary and fiscal policies; in the persistent potential output case the adjustment is similar but more gradual. In the hysteresis case, outcomes are more problematic as potential output is affected in the long run by this temporary shock. The hysteresis scenario in the model in other words is quite in line with the assertions of Summers and others on the Secular Stagnation hypothesis.

\subsection{Effects of changing the strength of fiscal stabilization}

The presence of hysteresis would a priori seem to strengthen the case for monetary and/or fiscal stabilization policies. In the no-hysteresis case (and the persistent potential output case with some delay), the economy will return to the original level of output when the shocks have been absorbed. Stabilization policies contribute only by speeding the adjustment back to the original output level. In the hysteresis case, the case for stabilisation is much stronger: stabilization policies can contribute in reducing the onset of hysteresis effects. This point has also repeatedly been made in the recent debates about 'self-defeating' fiscal austerity policies (see Delong and Summers (2012)) and about the need for unconventional monetary policies and quantitative easing.

It seems interesting to consider this debate about the role of fiscal stabilization in the Great Recession also in the context of our model. Figure 5 displays the effects of the same negative demand shock in period 1 as in Figure 1 under three alternative fiscal policy regimes. The blue line gives adjustment in the case of no automatic stabilisers in fiscal policy $(\mu=0)$, a "no policy" regime so to speak, the green lines give adjustment in the baseline case with average automatic stabilisers $(\mu=0.5)$, and red lines give the adjustment with strong fiscal stabilisation policy, $(\mu=1)$. We only consider here the case of strong hysteresis, $\alpha=1$ (the green lines in Figure 5 therefore correspond with the red lines in Figure 1).

It is clearly seen that if fiscal stabilization is stronger, hysteresis is less pronounced: in the nostabilization case (blue lines) the hysteresis effects on (potential) output are roughly double than those in case of the strongest fiscal stabilization (red lines).

The presence of hysteresis is also helpful understanding the possibility of 'self-defeating' fiscal austerity policies that has been attributed to the sovereign debt crisis in the Euro Area. The deterioration of public finances as a result of the financial crisis has led most Member States to adopt sizeable consolidation packages. Such fiscal consolidation strategies may turn out to be 'self-defeating' in the sense that the reduction in government expenditure could lead an even stronger fall in activity implying that fiscal performance indicators actually worsen. In the particular case here of our small model, think of the case an economy is facing recession as a result of a e.g. a temporary negative demand shock, and policy makers implement also fiscal austerity measures at the same time. This austerity policy could contribute to the onset of hysteresis effects. The resulting permanent drop in potential output and unemployment, aggravates also the budgetary position, which may end up to worsen rather than to improve the fiscal balance. 

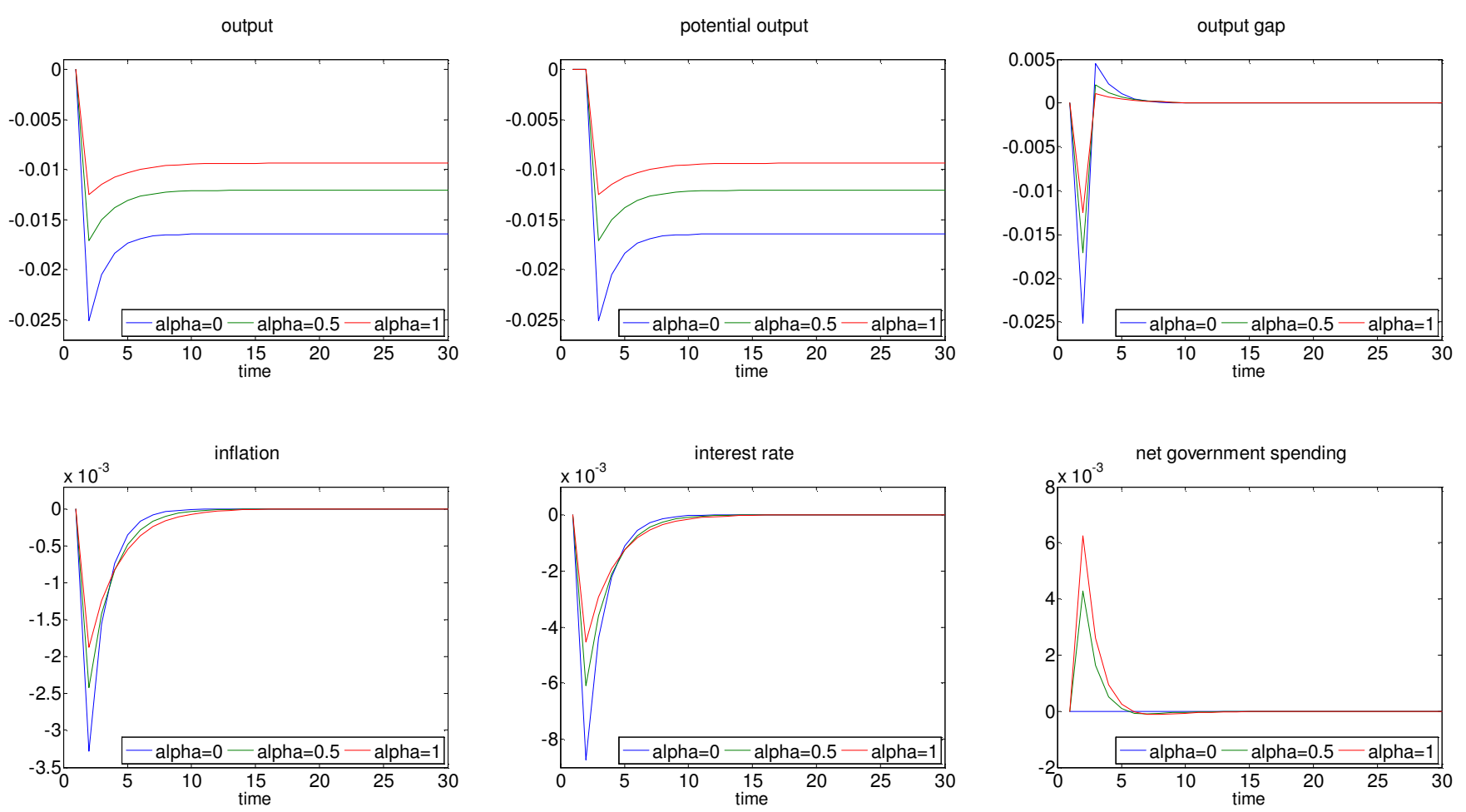

Figure 5: Effects of alternative degrees of fiscal stabilization.

\subsection{Counteracting the recession with structural reforms}

In response to the crisis, policy makers at the EU and OECD have amongst others also advocated the implementation of more ambitious structural reform programs especially in countries most severely affected by the Great Recession. In the setting of our model we interpret structural reforms as positive potential output shocks ${ }^{4}$. Figure 6 displays the case where the initial temporary negative demand shock in period 1 of Figure 1 is complemented by a temporary structural reform policy in period 2 .

The structural reform effort cushions the recession produced by the negative demand shock as is clear from from a comparison with Figure 1. Interestingly, the hysteresis regime now gives the best outcomes in the long-run: the negative hysteresis that would be produced from the temporary

\footnotetext{
${ }^{4}$ Structural reforms in that sense are comparable to positive technology shocks. For an insightful analysis on the effects of technology shocks in the New-Keynesian model, see Gali et al. (2003) and Ireland (2004).
} 



Figure 6: Effects of a temporary negative demand shock counteracted by a structural reform policy.

recession is surmounted in the long run by the positive effects on potential output from the structural reform. The presence of hysteresis in other words also raises the importance/possible benefits from structural reforms. Seen in this light, the recommendation of pursuing structural reform programs like the EU's Horizon2020 even in the presence of recession seems warranted.

\section{Conclusion}

Policymakers and academics have had a hard time recently in understanding the very shallow economic recovery ("Secular Stagnation") in most OECD countries from the global financial crisis and Great Recession. One of the most radical explanations that has been proposed is the hysteresis hypothesis, whose origin lies in the strong global recession of the early 1980s. In case hysteresis is present, temporary macroeconomic shocks may result in permanent effects. In that case, the economy is path-dependent and the case for macroeconomic stabilization policies is strongly enhanced compared to a non-hysteresis case standard. In case of hysteresis, adjustment is different as the 
economy would settle over time for a lower potential and actual output level due to the hysteresis channel.

Hysteresis increases also significantly the potential role for fiscal and monetary stabilization policies: these policies can contribute to moderating the eventual actual and potential output drop as a result of the temporary shock. In fact the entire logic of stabilization policies is affected: in the standard New-Keynesian (DSGE) model without hysteresis, stabilization policies serve to fine-tune macroeconomic adjustment thereby reducing the volatility in the adjustment to the long-run equilibrium that is unaffected by macroeconomic shocks. In the case hysteresis is added, stabilization policies are needed to reduce the (typically substantial) long-run impact from temporary shocks. In a similar vein, policy errors, like a procyclical fiscal deficit bias, are of a greater concern in case of hysteresis.

Our paper extended a basic New-Keynesian model by inserting hysteresis in potential output. With the model, a number of simulations of relevant scenarios was undertaken to illustrate the implications of hysteresis in the context of the Secular Stagnation hypothesis. It was demonstrated that such an extension has a number of crucial implications for macro-economic adjustment and macroeconomic management (compared to the standard New Keynesian model with constant potential output and a second case with persistent potential output). The simulations illustrated the central tenet of the hysteresis hypothesis: the possibility that temporary shocks, may have permanent effects in the economy: in particular a permanent drop in the level of potential output (and an increase in structural unemployment) is provoked affecting subsequently the broader economy. The hysteresis hypothesis has not only such implications in case of temporary demand shocks: our examples also considered temporary mark-up shocks and natural interest rate shocks.

In the final case, we reconsidered the policy advice to focus in particular on reviving structural reform agendas as the most appropriate instruments to recover from the Great Recession. In itself this approach make sense as it would contribute in principle to rebuilding productivity and potential output. Our final example revealed that the presence of hysteresis raises the importance/possible benefits from structural reforms. However, there is also a risk that reform efforts are annihilated if overly restrictive monetary and fiscal policies are present in an hysteretic economy.

Another important result from our simulation study relates to the (regained) importance of macroeconomic stabilization policies. It was demonstrated that if fiscal stabilization is stronger, the hysteresis channel is less pronounced/can be mitigated, a similar conclusion would pertain to the use of monetary policy as a tool of output stabilization, even if in that case there are also considerations relating to inflation stabilization. In that sense, the recent debates about 'self-defeating' fiscal austerity and the use of non-standard monetary policy measures by the ECB in the presence of a zero lower bound on interest rates can also be reinterpreted in the context of the hysteresis channel.

Our study did not provide any empirical evidence. Still, our take from the study is that in the case of the Euro Area the possibility of a hysteresis channel needs serious consideration: with monetary policy placed at the supra-national level and national fiscal policies restricted by a set of fiscal stringency requirements, there is a risk that hysteresis is particularly strong in countries that are hit by negative macroeconomic conditions. 


\section{References}

Anderton, B., T. Aranki, A. Dieppe, C. Elding, S. Haroutunian, P. Jacquinot, V. Jarvis, V. Labhard, D. Rusinova and B. Szrfi (2014), Potential output from a Euro Area perspective, European Central Bank Occasional Paper Series no.156.

Ball, L. (2014), Long-term damage from the Great Recession in OECD countries, European Journal of Economics and Economic Policies: Intervention, Vol. 11 No. 2, 2014, pp.149-160.

Blanchard, O. and C. Kahn (1980), The solution of linear difference models under rational expectations, Econometrica, vol.48, pp.1305-1311.

Blanchard, O. and L. Summers (1986), Hysteresis and the European Unemployment Problem, in S Fischer (ed), NBER Macroeconomics Annual, Vol. 1, Cambridge: MIT Press, pp.15-78.

Blanchard, O. and L. Summers (1987), Hysteresis in unemployment, European Economic Review, vol. 3, no.1-2, pp.288-295.

Blanchard, O. and L. Summers (1988), Beyond the natural rate hypothesis, American Economic Review, vol.78, no.2, pp.182-187.

Bruno, M. and J. Sachs (1985), Economics of worldwide stagflation, Cambridge: Harvard University press.

Delong, B. and L. Summers (2012), Fiscal policy in a depressed economy, Brookings Papers on Economic Activity, Spring 2012, pp.233-290.

Diebold, F. and G. Rudebusch (1987), Long memory and persistence in aggregate output, Journal of Monetary Economics, vol.24, pp.189-209.

Ehrmann, M. and F. Smets (2003), Uncertain potential output: Implications for monetary policy, Journal of Economic Dynamics and Control, vol.27, pp.1611-1638.

Gali, J., D. Lopez-Salido, J. Valles (2003), Technology shocks and monetary policy: assessing the Feds performance, Journal of Monetary Economics, vol.50, pp.723-743.

European Commission (2009), Impact of the current economic and financial crisis on potential output, European Economy, Occasional Papers no.49.

Furceri, D. and A. Mourougane (2012), The effect of financial crises on potential output: New empirical evidence from OECD countries, Journal of Macroeconomics, vol.34, pp.822-832.

Ireland, P. (2004), Technology shocks in the New Keynesian model, Review of Economics and Statistics, vol.86, no.4, pp.923-936.

Kienzler, D. and K. Schmid (2014), Hysteresis in potential output and monetary policy, Scottish Journal of Political Economy, vol.68, no.4, pp.371-396.

Klein, P. (2000), Using the generalized Schur form to solve a multivariate linear rational expectations model, Journal of Economic Dynamics and Control, vol.24, pp.1405-1423.

Lindbeck, A. and D. Snower (1986), Long-term unemployment and macroeconomic policy, American Economic Review, vol.78, no.2, pp.38-43.

OECD (2009), Beyond the crisis: Medium-term challenges relating to potential output, unemployment and fiscal positions, OECD Economic Outlook, vol.85, pp.211-241.

Ollivaud, P. and D. Turner (2014), The effect of the global financial crisis on OECD potential output, OECD Economics Department Working Papers, no.1166.

Stock. J. and M. Watson (1986), Does GNP have a unit root?, Economics Letters, vol.22, pp.147151.

Summers, L. (2014), U.S. economic prospects: Secular stagnation, hysteresis, and the zero lower bound, Business Economics, vol.49, no.2, pp.65-73.

Teulings, C. and R. Baldwin eds. (2014), Secular Stagnation: Facts, Causes and Cures, A 
VoxEU.org Book. London: CEPR Press.

\section{Appendix}

For analytical purposes it is convenient to write the macroeconomic model (1)-(5) in its statephase form. To do so, (3) and (4) are substituted into (1):

Let

$$
x_{t}^{\prime}=\left[y_{t}, \pi_{t}, \bar{y}_{t-1}, r_{t-1}^{n}, i_{t-1}, g_{t-1}\right]^{\prime}
$$

and

$$
v_{t}^{\prime}=\left[v_{t-1}^{y}, v_{t-1}^{\pi}, v_{t-1}^{i}, v_{t-1}^{g}, v_{t-1}^{r^{n}}, v_{t-1}^{\bar{y}}\right]^{\prime}
$$

then the model's state-phase is given by:

$$
E x_{t+1}=A x_{t}+B x_{t-1}+C v_{t+1}
$$

in which:

$A=\left[\begin{array}{cccccccccccc}\frac{\left.1+\sigma\left(1-\rho_{i}\right)-\left(1-\rho_{g}\right) \mu\right)}{\omega} & -\frac{\rho_{i}}{\omega} & -\frac{\left.\sigma\left(1-\rho_{i}\right)-\left(1-\rho_{g}\right) \mu\right)}{\omega} & \frac{\left(1-\rho_{i}\right)}{\omega} & 0 & 0 & -\frac{1}{\omega} & 0 & \frac{\sigma}{\omega} & -\frac{1}{\omega} & 0 & 0 \\ -\frac{\kappa}{\beta} & \frac{1}{\beta} & \frac{\kappa}{\beta} & 0 & 0 & 0 & 0 & -\frac{1}{\beta} & 0 & 0 & 0 & 0 \\ \alpha & 0 & (1-\alpha) \rho_{\bar{y}} & 0 & 0 & 0 & 0 & 0 & 0 & 0 & 0 & 1 \\ 0 & 0 & 0 & \rho_{r^{n}} & 0 & 0 & 0 & 0 & 0 & 0 & 1 & 0 \\ \left(1-\rho_{i}\right) \chi_{x} & \left(1-\rho_{i}\right) \chi_{\pi} & -\left(1-\rho_{i}\right) \chi_{x} & 1-\rho_{i} & \rho_{i} & 0 & 0 & 0 & 1 & 0 & 0 & 0 \\ \left(1-\rho_{g}\right) \mu & 0 & -\left(1-\rho_{g}\right) \mu & 0 & 0 & \rho_{g} & 0 & 0 & 0 & 1 & 0 & 0 \\ 0 & 0 & 0 & 0 & 0 & 0 & \nu_{\epsilon^{y}} & 0 & 0 & 0 & 0 & 0 \\ 0 & 0 & 0 & 0 & 0 & 0 & 0 & \nu_{\epsilon^{\pi}} & 0 & 0 & 0 & 0 \\ 0 & 0 & 0 & 0 & 0 & 0 & 0 & 0 & \nu_{\epsilon^{i}} & 0 & 0 & 0 \\ 0 & 0 & 0 & 0 & 0 & 0 & 0 & 0 & 0 & \nu_{\epsilon^{g}} & 0 & 0 \\ 0 & 0 & 0 & 0 & 0 & 0 & 0 & 0 & 0 & 0 & \nu_{\epsilon^{\bar{y}}} & 0 \\ 0 & 0 & 0 & 0 & 0 & 0 & 0 & 0 & 0 & 0 & 0 & \nu_{\epsilon^{n}}\end{array}\right]$,




$$
\begin{gathered}
B=\left[\begin{array}{cccccccccccc}
-\frac{1-\omega}{\omega} & 0 & 0 & 0 & \frac{\sigma \rho_{i}}{\omega} & \frac{\rho_{g}}{\omega} & 0 & 0 & 0 & 0 & 0 & 0 \\
0 & -\frac{1-\beta}{\beta} & 0 & 0 & 0 & 0 & 0 & 0 & 0 & 0 & 0 & 0 \\
0 & 0 & 0 & 0 & 0 & 0 & 0 & 0 & 0 & 0 & 0 & 0 \\
0 & 0 & 0 & 0 & 0 & 0 & 0 & 0 & 0 & 0 & 0 & 0 \\
0 & 0 & 0 & 0 & 0 & 0 & 0 & 0 & 0 & 0 & 0 & 0 \\
0 & 0 & 0 & 0 & 0 & 0 & 0 & 0 & 0 & 0 & 0 & 0 \\
0 & 0 & 0 & 0 & 0 & 0 & 0 & 0 & 0 & 0 & 0 & 0 \\
0 & 0 & 0 & 0 & 0 & 0 & 0 & 0 & 0 & 0 & 0 & 0 \\
0 & 0 & 0 & 0 & 0 & 0 & 0 & 0 & 0 & 0 & 0 & 0 \\
0 & 0 & 0 & 0 & 0 & 0 & 0 & 0 & 0 & 0 & 0 & 0 \\
0 & 0 & 0 & 0 & 0 & 0 & 0 & 0 & 0 & 0 & 0 & 0 \\
0 & 0 & 0 & 0 & 0 & 0 & 0 & 0 & 0 & 0 & 0 & 0
\end{array}\right], \\
\\
C=\left[\begin{array}{ccccccccc}
0 & 0 & 0 & 0 & 0 & 0 \\
0 & 0 & 0 & 0 & 0 & 0 \\
0 & 0 & 0 & 0 & 0 & 0 \\
0 & 0 & 0 & 0 & 0 & 0 \\
0 & 0 & 0 & 0 & 0 & 0 \\
0 & 0 & 0 & 0 & 0 & 0 \\
1 & 0 & 0 & 0 & 0 & 0 \\
0 & 1 & 0 & 0 & 0 & 0 \\
0 & 0 & 1 & 0 & 0 & 0 \\
0 & 0 & 0 & 1 & 0 & 0 \\
0 & 0 & 0 & 0 & 1 & 0 \\
0 & 0 & 0 & 0 & 0 & 1
\end{array}\right], \\
\end{gathered}
$$

Equation (6) describes a system of linear expectational difference equations. This system can be solved by uncoupling the unstable and stable components and then solving the unstable component forward and the stable component backward. There are a number of algorithms for working through this process as outlined by Klein (2000). Note that there are eight predetermined variables and two non predetermined variables in the vector $x_{t}$ and six predetermined variables in the vector $v_{t}$. Thus, if twelve of the generalized eigenvalues lie inside the unit circle and two of the generalized eigenvalues of the system lie outside the unit circle, the system has a unique solution. If more than two of the generalized eigenvalues lie outside the unit circle, then the system has no solution. If less than two of the generalized eigenvalues lie outside the unit circle, then the system has multiple solutions. See Blanchard and Kahn (1980) and Klein (2000) on this rank condition determining stability and nature of the system. In the baseline example of Table 1 that we use, the eigenvalues are:

There are 2 eigenvalue(s) larger than 1 in modulus for 2 forward-looking variable(s) so the rank condition is indeed verified. 


\begin{tabular}{|c|c|c|}
\hline Modulus & Real & Imaginary \\
\hline 0 & 0 & 0 \\
\hline 0 & 0 & 0 \\
\hline 0 & 0 & 0 \\
\hline 0 & 0 & 0 \\
\hline $9.819 \mathrm{e}-009$ & $9.819 \mathrm{e}-009$ & 0 \\
\hline $9.819 \mathrm{e}-009$ & $9.819 \mathrm{e}-009$ & 0 \\
\hline 0.5 & 0.5 & 0 \\
\hline 0.5 & 0.5 & 0 \\
\hline 0.5 & 0.5 & 0 \\
\hline 0.5 & 0.5 & 0 \\
\hline 0.5866 & 0.5866 & 0 \\
\hline 1.0 & 1.0 & 0 \\
\hline 1.239 & 1.207 & 0.2796 \\
\hline 1.239 & 1.207 & -0.2796 \\
\hline
\end{tabular}

Table 2: Eigenvalues of the system dynamics in case of the baseline parameter set. 